\title{
Analysis of 19 urinary biomarkers of oxidative stress, nitrative stress, metabolic disorders, and inflammation using liquid chromatography-tandem mass spectrometry
}

\author{
Maria-Pilar Martinez-Moral ${ }^{1,2,3,4}$ [D $\cdot$ Kurunthachalam Kannan ${ }^{3,4}$ (D)
}

Received: 30 September 2021 / Revised: 23 November 2021 / Accepted: 9 December 2021 / Published online: 11 January 2022

(c) Springer-Verlag GmbH Germany, part of Springer Nature 2022

\begin{abstract}
Environmental chemical exposures have been associated with cancer, diabetes, hormonal and immunological disorders, and cardiovascular diseases. Some direct effects of chemical exposure that are precursors to adverse health outcomes, including oxidative stress, nitrative stress, hormonal imbalance, neutrophilia, and eosinophilia, can be assessed through the analysis of biomarkers in urine. In this study, we describe a novel methodology for the determination of 19 biomarkers of health effects: malondialdehyde (MDA), 8-isoprostaglandin- $\mathrm{F}_{2 \alpha}\left(8-\mathrm{PGF}_{2 \alpha}\right), 11-\beta$-prostaglandin- $\mathrm{F}_{2 \alpha}\left(11-\mathrm{PGF}_{2 \alpha}\right), 15$-prostaglandin$\mathrm{F}_{2 \alpha}\left(15-\mathrm{PGF}_{2 \alpha}\right)$, 8-iso-15-prostaglandin- $\mathrm{F}_{2 \alpha}\left(8,15-\mathrm{PGF}_{2 \alpha}\right)$, 8-hydroxy-2'-deoxyguanosine (8-OHdG), 8-hydroxyguanosine (8-HdG), 8-hydroxyguanine (8-HG), dityrosine (diY), allantoin (Alla), and two metabolic products of 4-hydroxynonenal (HNE), namely 4-hydroxy-2-nonenal glutathione (HNE-GSH) and 4-hydroxy-2-nonenal mercapturic acid (HNE-MA) (in total, 12 oxidative stress biomarkers, OSBs); 8-nitroguanosine (8-NdG), 8-nitroguanine (8-NG), and 3-nitrotyrosine (NY) (3 nitrative stress biomarkers, NSBs); chlorotyrosine (CY) and bromotyrosine (BY) (2 inflammatory biomarkers); and the advanced glycation end-products (AGEs) $N^{\varepsilon}$-carboxymethyllysine (CML) and $N^{\varepsilon}$-carboxyethyllysine (CEL) (2 metabolic disorder biomarkers). Since these biomarkers are trigged by a variety of environmental insults and produced by different biomolecular pathways, their selective and sensitive determination in urine would help broadly elucidate the pathogenesis of diseases mediated by environmental factors.
\end{abstract}

Keywords ROS $\cdot$ RNS $\cdot$ Oxidative stress $\cdot$ Biomarkers $\cdot$ AGEs $\cdot$ Urine

\section{Introduction}

Environmental factors are known to contribute to a variety of adverse health outcomes in human and wildlife populations [1-4]. Nevertheless, molecular mechanisms underlying health effects due to exposure to environmental stressors remain poorly understood. Exposure to environmental

Kurunthachalam Kannan

kurunthachalam.kannan@nyulangone.org

1 Center for Biomedical Research of La Rioja (CIBIR), La Rioja, 26006 Logroño, Spain

2 Department of Chemistry, University of La Rioja, La Rioja, 26006 Logroño, Spain

3 Department of Pediatrics, New York University School of Medicine, New York, NY 10016, USA

4 Department of Environmental Medicine, New York University School of Medicine, New York, NY 10016, USA chemicals can inflict oxidative stress, nitrative stress, inflammation, and metabolic disorders, which are early events that occur well before the clinical diagnosis of diseases such as atherosclerosis, cancer, or neurodegenerative disorders [5-8]. Monitoring and assessment of early warning biomarkers of diseases are crucial to understanding pathogenesis following environmental insults. In particular, healtheffect biomarkers can be useful in illuminating relationships among environmental exposures, human physiology, and disease.

Biomarkers of health effects are commonly assessed by analyzing biospecimens such as blood or urine. Urine is widely used in monitoring exposure and effect biomarkers of a variety of environmental chemicals of concern. Studies have reported urinary biomarkers of oxidative stress, nitrative stress, eosinophilia, neutrophilia, and metabolic disorders as means to elucidate disease pathogenesis $[9,10]$.

Oxidative and nitrative stresses are associated with several diseases [8]. It is well known that concentrations of 
these stress markers increase in body tissues and fluids following exposure to environmental toxicants [11-16]. Reactive oxygen species (ROS) and reactive nitrogen species (RNS) are produced by the body at basal levels from metabolism, and these reactive species are normally neutralized by antioxidants. However, excessive production of ROS (e.g., superoxide anion $\left[\mathrm{O}_{2}{ }^{-}\right]$, hydrogen peroxide $\left[\mathrm{H}_{2} \mathrm{O}_{2}\right]$ ) and RNS (e.g., nitric oxide [NO], peroxynitrite $\left[\mathrm{ONOO}^{-}\right]$) above the antioxidant capacity of a biological system can arise from factors such as environmental stressors, medication, diet, smoking, and acute exercise. Excess ROS leads to oxidative stress, resulting in oxidative damage to biomolecules such as DNA and protein. The free radical $\mathrm{O}_{2}{ }^{-}$can react with $\mathrm{NO}$ to form $\mathrm{ONOO}^{-}$, a potent, diffusible radical that can react with amino acids, contributing to protein modifications such as nitration and nitrosylation. High levels of ROS and/or RNS can also cause lipid peroxidation, DNA damage, and oxidation/nitration of proteins that can activate inflammatory response, fibrosis, or cell death [8-10]. Therefore, a thorough understanding of the mechanisms that lead to perturbations in oxidative/nitrative status and their relationship to pro-inflammatory, hypertrophic, fibrotic, and apoptotic pathways would aid the development of strategies to counteract disease development and progression.

The quantitative determination of free radicals/ROS that contribute to oxidative/nitrative stress (ONS) is challenging due to their highly reactive nature and resulting transient lifespan in body tissues and fluids. However, the free radicals react with various biomolecules, and the products of these reactions can be detected in urine, blood, or feces. For instance, dityrosine (diY) and nitrotyrosine (NY) [17] are the products of protein damage caused by ROS and RNS, respectively. Oxidative damage to DNA by ROS can generate 8-hydroxy-2'-deoxyguanosine (8-OHdG) and 8-hydroxyguanine (8-HG), whereas that by RNS can yield 8-nitroguanine (8-NG). Reactions of ROS and RNS with RNA produce 8-hydroxyguanosine $(8-\mathrm{HdG})$ and 8 -nitroguanosine $(8-\mathrm{NdG})$, respectively $[12,14,18]$. The biomarkers of oxidative damage to polyunsaturated fatty acids (PUFA) by ROS are malondialdehyde (MDA) and 4-hydroxynonenal (HNE) [19, 20]; the oxidation of arachidonic acid (a fatty acid found in the liver, brain, and glands) can produce prostaglandin isomers, 8-isoprostaglandin $\mathrm{F}_{2 \alpha}\left(8-\mathrm{PGF}_{2 \alpha}\right)$, 11- $\beta$-prostaglandin $\mathrm{F}_{2 \alpha}\left(11-\mathrm{PGF}_{2 \alpha}\right)$, 15-prostaglandin $\mathrm{F}_{2 \alpha}$ (15- $\left.\mathrm{PGF}_{2 \alpha}\right)$, and 8-iso-15-prostaglandin $\mathrm{F}_{2 \alpha}\left(8,15-\mathrm{PGF}_{2 \alpha}\right)$ [21]; and uric acid oxidation yields allantoin (Alla) [22]. All of these reaction products are commonly excreted in urine.

Inflammation is a part of body's defense in response to injury or infection, but chronic inflammation, which can result from exposure to environmental chemicals, plays a key role in many disorders, such as autoimmune diseases and asthma [23-25]. Eosinophils and neutrophils are two types of white blood cells that are activated to fight diseases, infections, and inflammation. Eosinophilia and neutrophilia are conditions in which the number of eosinophils or neutrophils, respectively, increases above the normal levels in affected tissue [23, 26]. Under these conditions, neutrophil myeloperoxidase and eosinophil peroxidase overproduce halogenated species such as $\mathrm{HOCl}$ or $\mathrm{HOBr}$ that react with tyrosine, increasing chlorotyrosine (CY) [27, 28] and bromotyrosine (BY) [28] levels, which are recognized as inflammatory biomarkers (IBs) [17, 28].

Exposure to various environmental pollutants is linked to metabolic disorders [29]. Evidence indicates that metabolic disorders may be mediated through oxidative stress. Advanced glycation end-products (AGEs; proteins or lipids that become glycated from exposure to sugars) such as $N^{\varepsilon}$ MDA- $\mathrm{d}_{2}(\mathrm{CML})$ and $N^{\varepsilon}$-carboxyethyllysine (CEL) are biomarkers of metabolic disorders or diseases [20].

Earlier methods to analyze health-effect biomarkers entailed testing for a single class of chemicals at a time. However, the simultaneous determination of urinary concentrations of multiple biomarkers of health effects, such as oxidative stress (OSBs), nitrative stress (NSBs), eosinophilia (EB), and neutrophilia (NB) along with AGEs, would help advance the knowledge of disease pathogenesis. Because different biomarkers are generated in organisms from various molecular pathways, after exposure to multiple radicals (or radical-producing stressors) that damage proteins, lipids, uric acid, DNA, RNA, or sugars, concurrent and broader testing can provide comprehensive information about the events mediating disease progression (Fig. 1; Table 1).

In addition, evidence supports interplay between biomarkers [20], and therefore, simultaneous analyses of multiple biomarkers are crucial for comprehensive understanding of disease pathogenesis. For example, although the generation of AGEs (glycation of proteins or lipids) is known to be mediated by elevated ROS [30], the interactions involved are poorly understood due to the fact that analytical methods to measure multiple effect biomarkers simultaneously were not available. Moreover, selection of reliable biomarkers of a disease is possible only when multiple biomarkers are analyzed simultaneously.

In this study, we developed a sensitive and selective analytical method for simultaneous determination of 16 effect biomarkers-namely, 11 biomarkers that report levels of oxidative stress, diY, 8-OHdG, 8-HG, 8-HdG, 8-PGF $2 \alpha$, 11-PGF ${ }_{2 \alpha}, 15-\mathrm{PGF}_{2 \alpha}, 8,15-\mathrm{PGF}_{2 \alpha}, \mathrm{MDA}, 4$-hydroxynonenal glutathione (HNE-GHS), and 4-hydroxynonenal mercapturic acid (HNE-MA); three for nitrative stress, NY, 8-NG, and 8-NdG; one each for eosinophil (BY) and neutrophil (CY) activation. The determination of Alla and two biomarkers of metabolic disorders (CML and CEL) was accomplished using dilute and shoot (D\&S) method to enable analysis of 19 biomarkers in urine using high-performance liquid chromatography-tandem mass spectrometry (HPLC-MS/MS). 
Fig. 1 Schematic representation of the sources and pathways of formation of various health effect biomarkers, such as oxidative stress, nitrative stress, eosinophilia, neutrophilia, and metabolic disorders in the human body

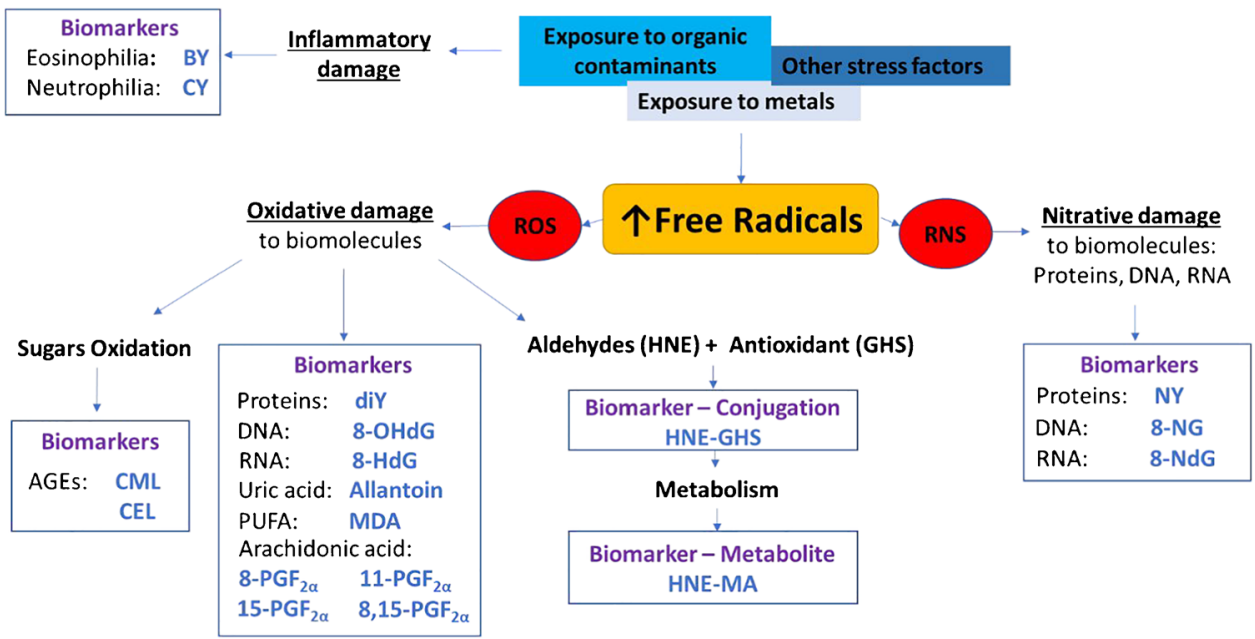

This methodology is suitable for application in large-scale human biomonitoring studies.

\section{Materials and methods}

\section{Standards and chemicals}

HPLC-grade methanol, acetonitrile, water, and ethyl acetate were purchased from Fisher Scientific (Pittsburgh, PA, USA). Synthetic urine, 2,4-dinitrophenylhydrazine (DNPH; $\geq 99 \%$ purity), 8-hydroxy-2'-deoxyguanosine (8-OHdG; $\geq 98 \%$ ), 3-chloro-L-tyrosine (CY; 97\%), and malondialdehyde tetrabutylammonium salt (MDA; 97\%) were obtained from Sigma-Aldrich (St. Louis, MO, USA). The analytical standards 4-hydroxynonenal glutathione (trifluoroacetate salt) (HNE-GSH; $\geq 95 \%$ ), 4-hydroxynonenal mercapturic acid (HNE-MA; $\geq 98 \%$ ), 8-isoprostaglandin $\mathrm{F}_{2 \alpha}\left(8-\mathrm{PGF}_{2 \alpha} ; \geq 99 \%\right), 11-\beta$-prostaglandin $\mathrm{F}_{2 \alpha}(11-$ $\left.\mathrm{PGF}_{2 \alpha} ; \geq 98 \%\right)$, 15-prostaglandin $\mathrm{F}_{2 \alpha}\left(15-\mathrm{PGF}_{2 \alpha} ; \geq 98 \%\right)$, 8-iso-15-prostaglandin $\mathrm{F}_{2 \alpha}\left(8,15-\mathrm{PGF}_{2 \alpha} ; \geq 98 \%\right)$, 8-hydroxyguanosine (8-HdG; $\geq 98 \%)$, 8-hydroxyguanine (hydrochloride) (8-HG; $\geq 90 \%), 8$-nitroguanine (8-NG; $\geq 95 \%$ ), nitrotyrosine (NY; $\geq 98 \%$ ), and 3-bromotyrosine (trifluoroacetate salt) (BY; $\geq 95 \%)$ and the internal standards 4-hydroxynonenal mercapturic acid- $\mathrm{d}_{3}$ (HNE-MA- $\left.\mathrm{d}_{3} ; \geq 99 \%\right)$, 4-hydroxynonenal glutathione- $d_{3}$ (trifluoroacetate salt) (HNE-GSH- $\mathrm{d}_{3} ; \geq 99 \%$ ), 8-isoprostaglandin $\mathrm{F}_{2 \alpha}-\mathrm{d}_{4}$ ( $\geq 99 \%$ ), and 3-bromotyrosine- ${ }^{13} \mathrm{C}_{9},{ }^{15} \mathrm{~N}$ (trifluoroacetate salt) (BY- ${ }^{13} \mathrm{C}_{9},{ }^{15} \mathrm{~N} ; \geq 98 \%$ ) were purchased from Cayman Chemicals (Ann Arbor, MI, USA). Allantoin (Alla; 98\%), o, $o^{\prime}$-dityrosine dihydrochloride (diY; 95\%), $N^{\varepsilon}$-(1carboxyethyl)-L-lysine (CEL; 96\%), $N^{\varepsilon}$-(1-carboxymethyl)-Llysine (CML; 97\%), and 8-nitroguanosine (8-NdG; 96\%) and the internal standards allantoin- ${ }^{13} \mathrm{C}_{2},{ }^{15} \mathrm{~N}_{4}$ (Alla $-{ }^{13} \mathrm{C}_{2},{ }^{15} \mathrm{~N}_{4}$; $98 \%)$, and $N^{\varepsilon}-\left(1\right.$-carboxymethyl)-L-lysine-d ${ }_{4}\left(\mathrm{CML}-\mathrm{d}_{4} ; 96 \%\right)$ were obtained from Toronto Research Chemicals (Guelph, Ontario, Canada). $o, o^{\prime}$-Dityrosine- $-{ }^{13} \mathrm{C}_{12}\left(\mathrm{diY}_{-}{ }^{13} \mathrm{C}_{12} ; 99 \%\right)$, 3-nitro-L-tyrosine- ${ }^{13} \mathrm{C}_{6}\left(\mathrm{NY}^{-13} \mathrm{C}_{6} ; \geq 94 \%\right)$, and 8-hydroxy-2'deoxyguanosine- $-{ }^{15} \mathrm{~N}_{5}\left(8-\mathrm{OHdG}-{ }^{15} \mathrm{~N}_{5} ; 95 \%\right)$ were purchased from Cambridge Isotope Laboratories (Tewksbury, MA, USA). Malondialdehyde-1,3- $\mathrm{d}_{2}$-bis(diethyl acetal) (MDA$\mathrm{d}_{2} ; 98 \%$ ) was from C/D/N Isotopes (Pointe-Claire, Quebec, Canada).

A working standard mixture containing $1000 \mathrm{ng} \mathrm{mL}^{-1}$ of each native compound was prepared in 50:50 (v/v) methanol:water. An internal standard mixture at a concentration of $1000 \mathrm{ng} \mathrm{mL}^{-1}$ was prepared from individual stock solutions of HNE-MA- $\mathrm{d}_{3}$, HNE-GHS- $\mathrm{d}_{3}$, MDA- $\mathrm{d}_{2}$, 8 -PGF $2 \alpha-\mathrm{d}_{4}, \mathrm{BY}^{-13} \mathrm{C}_{9},{ }^{15} \mathrm{~N}, \mathrm{NG}-{ }^{13} \mathrm{C}_{2},{ }^{15} \mathrm{~N}, \mathrm{diY}-{ }^{13} \mathrm{C}_{12}$, NY${ }^{13} \mathrm{C}_{6}$, and $8-\mathrm{OHdG}^{-15} \mathrm{~N}_{5}$. Individual working standards containing Alla- ${ }^{13} \mathrm{C}_{2},{ }^{15} \mathrm{~N}_{4}$ and CML- $\mathrm{d}_{4}$ were used for the determination of Alla and AGEs, respectively.

\section{Analysis}

The determination of urinary biomarkers of oxidative and nitrative stress, as well as inflammation, was accomplished through solid-phase extraction (SPE) followed by HPLC-MS/MS analysis as previously reported [31], with modifications. An earlier method was validated in our laboratory for seven OSBs, and the method here includes an additional 9 OSB/NSB biomarkers, for a total of 16 OSB/ NSB/IB biomarkers. Separate methods were developed for the analysis of Alla and AGEs.

\section{Analysis of 16 urinary OSBs/NSBs/IBs}

An aliquot of $0.5 \mathrm{~mL}$ urine was transferred into a polypropylene (PP) tube, and $10 \mu \mathrm{L}$ of a solution containing $1000 \mathrm{ng} \mathrm{mL}^{-1}$ of each internal standard, as well as 100 $\mu \mathrm{L}$ of $0.005 \mathrm{M}$ DNPH (derivatization reagent) solution, 
Table 1 Sources and structures of urinary chemical biomarkers of health effects analyzed in this study

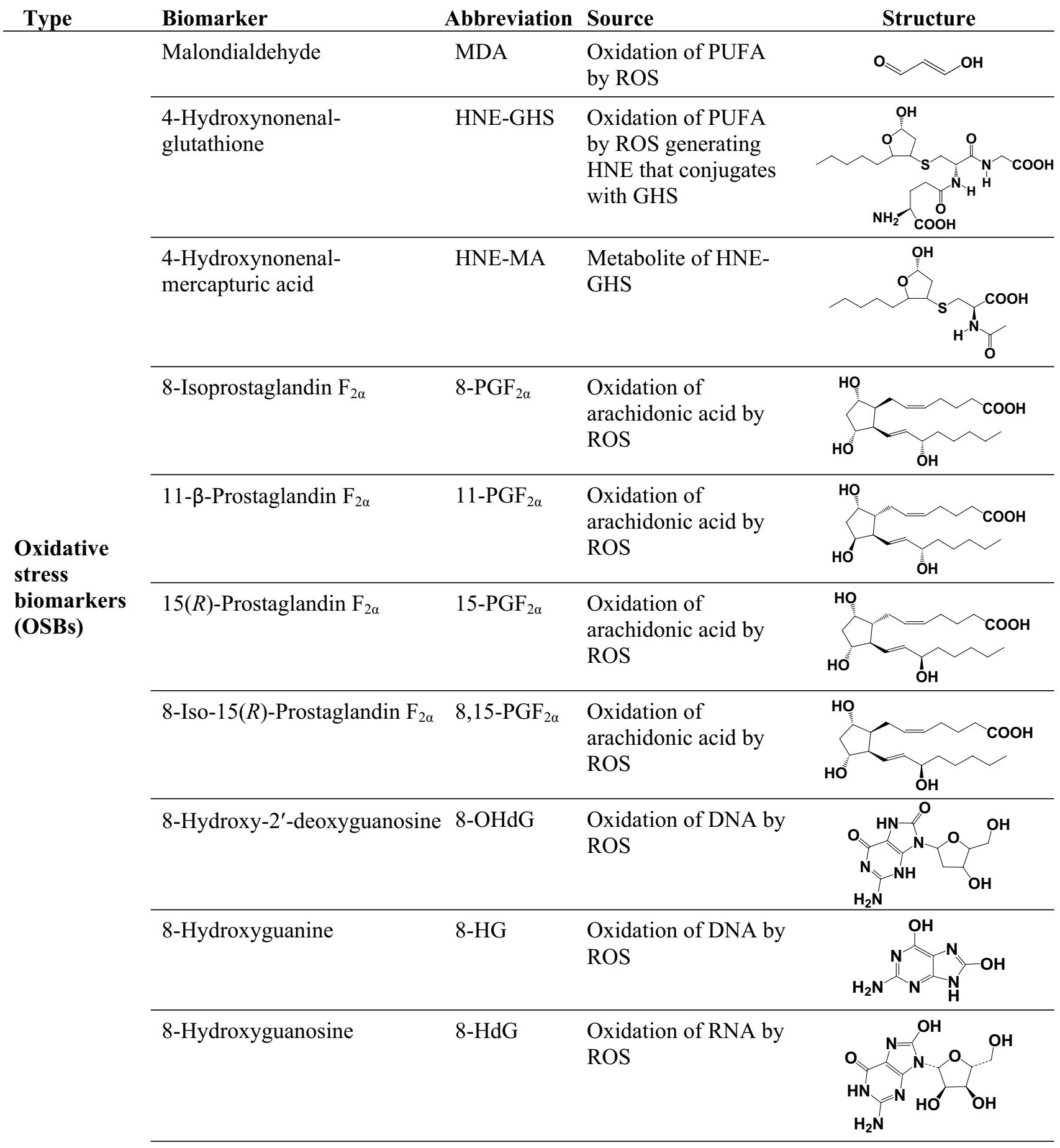

was added. Samples were incubated at room temperature $\left(22{ }^{\circ} \mathrm{C}\right)$ for $30 \mathrm{~min}$, and then, $1 \mathrm{~mL}$ of water was added in preparation for SPE. ABS ElutNexus cartridges $(60 \mathrm{mg}$, $3 \mathrm{~mL}$ ) (Agilent, Santa Clara, CA, USA) were cleaned and conditioned with $2 \mathrm{~mL}$ of methanol followed by $2 \mathrm{~mL}$ of HPLC-grade water. The derivatized sample then was passed through the cartridge and washed with $2 \mathrm{~mL}$ of 95:5 (v/v) water:methanol. Cartridges were vacuum dried and eluted with $1 \mathrm{~mL}$ methanol followed by $1 \mathrm{~mL}$ ethyl acetate, which were collected in the same tube. Eluates were dried under a gentle nitrogen stream at room temperature, reconstituted with $0.2 \mathrm{~mL}$ of 8:2 (v/v) water:methanol, and centrifuged, and finally, $20 \mu \mathrm{L}$ of the sample was injected into the HPLC-MS/MS instrument.

The MS was operated in both positive and negative ionization modes, and compound-specific MS/MS parameters 
Table 1 (continued)

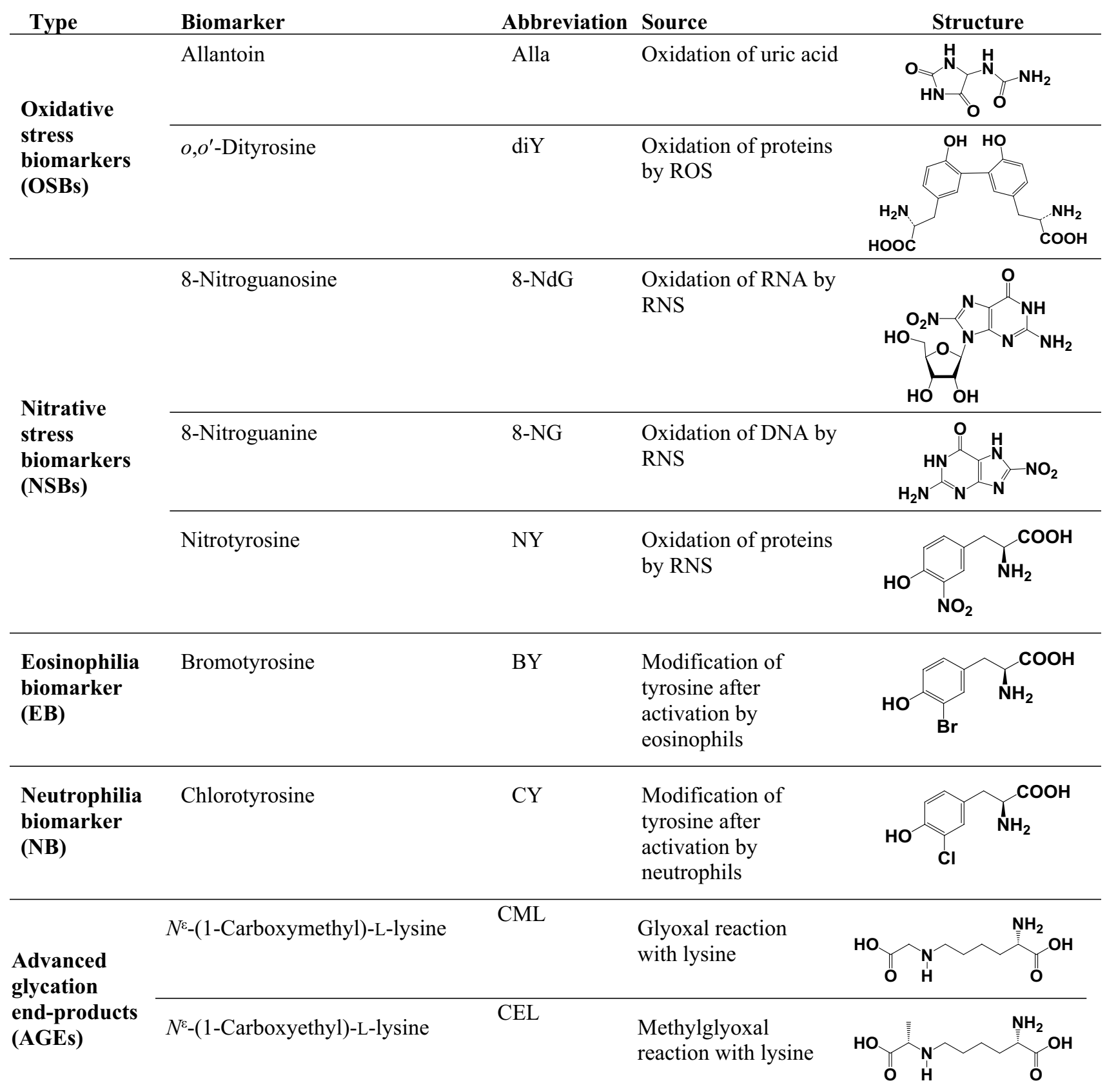

$R O S$, reactive oxygen species; $R N S$, reactive nitrogen species; $P U F A$, polyunsaturated fatty acids

were optimized by infusion of individual standard solutions (Table 2). The most abundant MS/MS transition was selected as quantitative, and the second most abundant was selected as the qualitative ion, especially for those compounds that did not have corresponding labeled internal standard (and therefore required a confirmation ion). An Agilent 1260 HPLC instrument (Agilent, Santa Clara, CA, USA), connected with an Eclipse Plus C18 (particle size $3.5 \mu \mathrm{m} ; 4.6 \times 100 \mathrm{~mm}$ ) column (Agilent, Santa Clara, CA, USA) and a Betasil C18 guard column (particle size $5 \mu \mathrm{m}$;
$4.6 \times 10 \mathrm{~mm}$ ), and interfaced with an ABSCIEX triple quadrupole $5500 \mathrm{MS}$ (Sciex, Framingham, MA, USA), with a Turbo $\mathrm{V}$ ionization source was used in the analysis. Electrospray positive ionization conditions were set as follows: curtain gas (CUR) 50 psi, collision-activated dissociation gas (CAD) 10 psi, temperature $450^{\circ} \mathrm{C}$, nebulizer gas (GS1) $50 \mathrm{psi}$, and turbo ion spray voltage (IS) $4500 \mathrm{~V}$. For the duration of the negative ionization, temperature was set at $500{ }^{\circ} \mathrm{C}$ and turbo ion spray voltage was set at $-4500 \mathrm{~V}$. Liquid chromatographic separation was accomplished at room 
Table 2 Optimized HPLC-MS/MS parameters for the analysis of 19 biomarkers and corresponding internal standards determined in urine in this study

\begin{tabular}{|c|c|c|c|c|c|c|c|c|}
\hline Biomarker & MW & $\mathrm{RT}(\min )$ & Mode & MRM transition $(\mathrm{m} / \mathrm{z})$ & $\mathrm{DP}(\mathrm{V})$ & $\mathrm{EP}(\mathrm{V})$ & $\mathrm{CE}(\mathrm{V})$ & $\mathrm{CXP}(\mathrm{V})$ \\
\hline MDA-DNPH & 234 & 11.6 & + & $\begin{array}{l}235>159 \\
235>189^{a}\end{array}$ & 30 & 8 & 30 & 3 \\
\hline $\mathrm{D}_{2}$-MDA-DNPH & 236 & 11.6 & + & $237>161$ & 30 & 8 & 30 & 3 \\
\hline HNE-GHS & 463 & $8.9+9.1+9.4$ & + & $\begin{array}{l}464>308 \\
464>446^{\mathrm{a}}\end{array}$ & 25 & 10 & 18 & 12 \\
\hline $\mathrm{D}_{3}$-HNE-GHS & 466 & $8.9+9.1+9.4$ & + & $467>308$ & 25 & 10 & 18 & 12 \\
\hline HNE-MA & 319 & 12.4 & - & $\begin{array}{l}318>171 \\
318>189^{\mathrm{a}}\end{array}$ & -80 & -10 & -27 & -12 \\
\hline $\mathrm{D}_{3}$-HNE-MA & 322 & 12.4 & - & $321>174$ & -80 & -10 & -27 & -12 \\
\hline $8-\mathrm{PGF}_{2 \alpha}$ & 354 & 15.8 & - & $\begin{array}{l}353>193 \\
353>247^{\mathrm{a}}\end{array}$ & -40 & -8 & -30 & -12 \\
\hline $11-\mathrm{PGF}_{2 \alpha}$ & 354 & 16.0 & - & $\begin{array}{l}353>193 \\
353>247^{\mathrm{a}}\end{array}$ & -40 & -8 & -30 & -12 \\
\hline $15-\mathrm{PGF}_{2 \alpha}$ & 354 & 16.2 & - & $\begin{array}{l}353>193 \\
353>247^{\mathrm{a}}\end{array}$ & -40 & -8 & -30 & -12 \\
\hline $8,15-\mathrm{PGF}_{2 \alpha}$ & 354 & 15.6 & - & $\begin{array}{l}353>193 \\
353>247^{\mathrm{a}}\end{array}$ & -40 & -8 & -30 & -12 \\
\hline $\mathrm{D}_{4}-8-\mathrm{PGF}_{2 \alpha}$ & 358 & 15.8 & - & $357>197$ & -40 & -8 & -30 & -12 \\
\hline 8-OHdG & 283 & 6.2 & + & $\begin{array}{l}284>168 \\
284>140^{\mathrm{a}}\end{array}$ & 25 & 3 & 18 & 4 \\
\hline${ }^{15} \mathrm{~N}_{5}-8-\mathrm{OHdG}$ & 288 & 6.2 & + & $289>173$ & 25 & 3 & 18 & 4 \\
\hline 8-HG & 167 & 6.2 & + & $\begin{array}{l}168>140 \\
168>112^{\mathrm{a}}\end{array}$ & 25 & 10 & 21 & 12 \\
\hline 8-HdG & 299 & 5.9 & + & $\begin{array}{l}300>168 \\
300>140^{\mathrm{a}}\end{array}$ & 25 & 10 & 21 & 12 \\
\hline $\operatorname{diY}$ & 360 & 5.5 & + & $\begin{array}{l}361>315 \\
361>283^{\mathrm{a}}\end{array}$ & 35 & 10 & 22 & 12 \\
\hline${ }^{13} \mathrm{C}_{12}$-diY & 372 & 5.5 & + & $373>327$ & 35 & 10 & 22 & 12 \\
\hline 8-NG & 196 & 6.3 & + & $\begin{array}{l}197>151 \\
197>179^{\mathrm{a}}\end{array}$ & 21 & 10 & 10 & 12 \\
\hline $8-\mathrm{NdG}$ & 328 & 6.6 & + & $\begin{array}{l}329>151 \\
329>197^{\mathrm{a}}\end{array}$ & 20 & 10 & 40 & 12 \\
\hline NY & 226 & 6.7 & + & $\begin{array}{l}227>117 \\
227>181^{\mathrm{a}}\end{array}$ & 25 & 10 & 20 & 12 \\
\hline${ }^{13} \mathrm{C}_{6}-\mathrm{NY}$ & 232 & 6.7 & + & $233>122$ & 25 & 10 & 18 & 12 \\
\hline BY & 259 & 6.5 & + & $\begin{array}{l}260>243 \\
260>214^{\mathrm{a}}\end{array}$ & 25 & 10 & 15 & 12 \\
\hline${ }^{13} \mathrm{C}_{9},{ }^{15} \mathrm{~N}-\mathrm{BY}$ & 269 & 6.5 & + & $270>252$ & 30 & 10 & 16 & 12 \\
\hline $\mathrm{CY}$ & 215 & 6.2 & + & $\begin{array}{l}216>199 \\
216>170^{a}\end{array}$ & 25 & 10 & 14 & 12 \\
\hline Alla & 158 & 4.2 & + & $\begin{array}{l}159>116 \\
159>99^{\mathrm{a}}\end{array}$ & 30 & 3 & 10 & 3 \\
\hline${ }^{13} \mathrm{C}_{2},{ }^{15} \mathrm{~N}_{4}$-Alla & 164 & 4.2 & + & $165>120$ & 30 & 3 & 10 & 3 \\
\hline CEL & 218 & 4.1 & + & $\begin{array}{l}219>84 \\
219>130^{\mathrm{a}}\end{array}$ & 30 & 7 & 25 & 12 \\
\hline CML & 204 & 4.0 & + & $\begin{array}{l}205>84 \\
205>130^{a}\end{array}$ & 40 & 7 & 20 & 12 \\
\hline $\mathrm{D}_{4}$-CML & 208 & 4.0 & + & $209>88$ & 35 & 7 & 25 & 12 \\
\hline
\end{tabular}

${ }^{\mathrm{a}}$ Confirmation ion transition

$D P$, declustering potential; $E P$, entrance potential; $C E$, collision energy; $C X P$, exit potential; $M W$, molecular weight; $R T$, retention time 
temperature. The mobile phase consisted of $0.1 \%$ acetic acid in water (phase A) and 8:2(v/v) methanol:acetonitrile containing $0.1 \%$ acetic acid (phase B). The flow was initially set at $100 \% \mathrm{~A}$ at $500 \mu \mathrm{L} \mathrm{min}{ }^{-1}$, held for $2 \mathrm{~min}$, and then decreased to $50 \%$ A over the next $3 \mathrm{~min}$, to $35 \%$ A over $6 \mathrm{~min}$, to $30 \%$ A for $9 \mathrm{~min}$, and to $0 \%$ over the final $1 \mathrm{~min}$. The flow was then continued with $100 \%$ B (0\% A) for 6 min. The gradient composition was then reverted to the original $100 \% \mathrm{~A}$ for the last $9 \mathrm{~min}$ to equilibrate the column, for a total run time of $36 \mathrm{~min}$.

\section{Method validation}

The linearity, sensitivity, matrix effect, accuracy, and precision of the analytical method were assessed. The linear regression parameters were obtained from the analysis of urine spiked at concentrations near the expected limits of detection and quantification for the calculation of method limit of detection (mLOD) and method limit of quantification (mLOQ) for each biomarker. mLOD and mLOQ were calculated as 3 and 10 times of the $S_{\mathrm{b}} / a$ respectively $\left(S_{\mathrm{b}}\right.$ : intercept standard deviation, $a$ : slope).

Method validation was accomplished through the analysis of synthetic urine and a pool of real urine, each fortified with standard analytes at three different concentrations (low, A; medium, B; high, C) and analyzed in triplicate for 3 days for the determination of precision and accuracy. The fortified concentrations of analytes for method validation were set based on the mLOD and expected concentrations in urine. For 8- $\mathrm{PGF}_{2 \alpha}, 11-\mathrm{PGF}_{2 \alpha}, 15-\mathrm{PGF}_{2 \alpha}, 8,15-\mathrm{PGF}_{2 \alpha}$, 8-OHdG, and 8-NdG, the low (A), medium (B), and high (C) fortification levels were $0.1,1.0$, and $10.0 \mathrm{ng} \mathrm{mL}^{-1}$, respectively. For 8-HG, 8-HdG, diY, 8-NG, NY, BY, CY, MDA and HNE-GHS, the fortification levels were A, $0.5 \mathrm{ng} \mathrm{mL}^{-1}$; B, $5.0 \mathrm{ng} \mathrm{mL}^{-1}$; and $\mathrm{C}, 10.0 \mathrm{ng} \mathrm{mL}^{-1}$; and those for HNE-MA were A, $5.0 \mathrm{ng} \mathrm{mL}^{-1}$; B, $10.0 \mathrm{ng} \mathrm{mL}^{-1}$; and $\mathrm{C}, 50.0 \mathrm{ng} \mathrm{mL}^{-1}$. The analysis of variance (ANOVA) of the data obtained from three replicate samples analyzed over 3 different days was used to calculate intra-day and inter-day precision (RSD, \%) at the three levels. Accuracy was calculated in terms to recovery $(\%)$ at the lowmedium-high fortification levels. The method validation for linearity (coefficient of determination, $R^{2}$ ), sensitivity (mLOD and $\mathrm{mLOQ}$ ), precision (intra-day and inter-day $\mathrm{RSD}, \%$ ), and accuracy (\% recovery) at the three fortification levels (A, B, and C) is shown in Table 3 .

\section{Determination of allantoin and creatinine}

Due to the high polarity of Alla and $\mathrm{Cr}$, and their high concentrations relative to those of other target analytes in urine, these two biomarkers were determined by following a method described earlier [22].
Table 3 Precision,

accuracy, sensitivity, and linearity of the analytical method assessed at three different concentrations (A, low; $\mathrm{B}$, medium; $\mathrm{C}$, high; see text for actual concentrations) in the determination of urine biomarkers of oxidative stress, nitrative stress, metabolic disorders, and inflammation

\begin{tabular}{|c|c|c|c|c|c|c|c|c|c|c|c|c|}
\hline \multirow[t]{2}{*}{ Biomarker } & \multicolumn{3}{|c|}{$\begin{array}{l}\text { Intra-day } \\
\text { repeatability } \\
(\%, \mathrm{RSD})\end{array}$} & \multicolumn{3}{|c|}{$\begin{array}{l}\text { Inter-day } \\
\text { repeatability } \\
(\%, \mathrm{RSD})\end{array}$} & \multicolumn{3}{|c|}{ Recovery (\%) } & \multirow[t]{2}{*}{$\begin{array}{l}\mathrm{mLOD} \\
\left(\mathrm{ng} \mathrm{mL}^{-1}\right)\end{array}$} & \multirow[t]{2}{*}{$\begin{array}{l}\mathrm{mLOQ} \\
\left(\mathrm{ng} \mathrm{mL}^{-1}\right)\end{array}$} & \multirow[t]{2}{*}{$R^{2}$} \\
\hline & $\mathrm{A}$ & $\mathrm{B}$ & $\mathrm{C}$ & $\mathrm{A}$ & B & $\mathrm{C}$ & $\mathrm{A}$ & B & $\mathrm{C}$ & & & \\
\hline MDA-DNPH & 11 & 6 & 1 & 15 & 11 & 3 & 91 & 102 & 115 & 0.08 & 0.27 & 0.9992 \\
\hline HNE-GHS & 9 & 6 & 5 & 7 & 6 & 5 & 101 & 115 & 113 & 0.03 & 0.11 & 0.9998 \\
\hline HNE-MA & 6 & 7 & 4 & 7 & 4 & 4 & 105 & 105 & 102 & 0.36 & 1.20 & 0.9998 \\
\hline $8-\mathrm{PGF}_{2 \alpha}$ & 7 & 8 & 2 & 9 & 9 & 5 & 94 & 96 & 94 & 0.013 & 0.04 & 0.9998 \\
\hline $11-\mathrm{PGF}_{2 \alpha}$ & 13 & 3 & 6 & 5 & 5 & 5 & 119 & 116 & 117 & 0.014 & 0.05 & 0.9998 \\
\hline $15-\mathrm{PGF}_{2 \alpha}$ & 7 & 6 & 9 & 6 & 10 & 14 & 109 & 111 & 110 & 0.013 & 0.04 & 0.9998 \\
\hline $8,15-\mathrm{PGF}_{2 \alpha}$ & 6 & 8 & 9 & 4 & 9 & 3 & 89 & 91 & 100 & 0.013 & 0.05 & 0.9998 \\
\hline 8-OHdG & 6 & 4 & 6 & 2 & 3 & 3 & 103 & 110 & 107 & 0.023 & 0.08 & 0.9998 \\
\hline 8-HG & 8 & 9 & 7 & 6 & 8 & 5 & 104 & 106 & 95 & 0.03 & 0.11 & 0.9994 \\
\hline 8-HdG & 3 & 9 & 1 & 4 & 10 & 10 & 100 & 100 & 90 & 0.04 & 0.12 & 0.9994 \\
\hline $\operatorname{diY}$ & 8 & 10 & 9 & 6 & 8 & 11 & 114 & 114 & 102 & 0.06 & 0.20 & 0.9992 \\
\hline 8-NG & 11 & 7 & 6 & 9 & 14 & 5 & 88 & 95 & 88 & 0.05 & 0.18 & 0.9998 \\
\hline 8-NdG & 9 & 12 & 8 & 3 & 5 & 14 & 92 & 109 & 107 & 0.03 & 0.09 & 0.9994 \\
\hline NY & 6 & 4 & 4 & 12 & 11 & 4 & 98 & 91 & 82 & 0.05 & 0.15 & 0.9998 \\
\hline BY & 10 & 7 & 7 & 12 & 9 & 11 & 89 & 109 & 99 & 0.06 & 0.19 & 0.9998 \\
\hline CY & 8 & 10 & 6 & 7 & 10 & 8 & 94 & 106 & 110 & 0.09 & 0.30 & 0.9992 \\
\hline CML & 3 & 7 & 3 & 7 & 7 & 9 & 97 & 94 & 91 & 0.13 & 0.43 & 0.9998 \\
\hline CEL & 3 & 8 & 4 & 14 & 14 & 12 & 93 & 91 & 90 & 0.18 & 0.59 & 0.9996 \\
\hline
\end{tabular}




\section{Determination of AGEs in urine}

CML and CEL were analyzed using a D\&S method. Urine samples were diluted at 1:100 with HPLCgrade water; $10 \mu \mathrm{L}$ of an internal standard, $\mathrm{CML}-\mathrm{d}_{4}$ (1000 $\mathrm{ng} \mathrm{mL} \mathrm{m}^{-1}$ ), was added, and the samples were injected on the HPLC-MS/MS instrument. The MS parameters were optimized as described above. A Luna C18 (3 $\mathrm{m}, 4.6 \times 100 \mathrm{~mm}$; Phenomenex, Torrance, CA, USA) column connected to a Betasil C18 guard column $(5 \mu \mathrm{m} ; 4.6 \times 10 \mathrm{~mm})$ was used for chromatographic separation. The mobile-phase gradient flow consisted of $100 \%$ A $(0.1 \%$ acetic acid in water $)$ held for $4 \mathrm{~min}$, increased to $100 \% \mathrm{~B}(0.1 \%$ acetic acid in methanol) over $1 \mathrm{~min}$ and held for $2 \mathrm{~min}$ (for column cleaning), and then returned to the initial $100 \% \mathrm{~A}$ over $1 \mathrm{~min}$ and held for $4 \mathrm{~min}$ (for column stabilization). The mobile-phase flow was set at $350 \mu \mathrm{L} \mathrm{min}{ }^{-1}$. Total analysis time was $12 \mathrm{~min}$, and the MS data were acquired from 2 to 6 min after the start of flow.

Instrument parameters and select chromatograms of target analytes are shown in Table 2 and Fig. 2, respectively. Method validation for CML and CEL was performed by fortifying synthetic and real urine samples with standard analytes at three different concentrations and classifying their concentrations as low, $1 \mathrm{ng} \mathrm{mL}{ }^{-1}$; medium, $10 \mathrm{ng} \mathrm{mL}^{-1}$; or high, $50 \mathrm{ng} \mathrm{mL}^{-1}$. The results for precision, sensitivity, and accuracy of the method are presented in Table 3 .

\section{Urine samples}

For method development and validation, a pool of real urine from 10 volunteers (50\% males and 50\% females) was used. Urine samples collected from healthy volunteers in Albany, NY, USA, in 2018 ( $n=20,10$ males and 10 females; ages 11-56 years) were analyzed according to the method developed, to demonstrate its feasibility. Urine samples were kept at $-80{ }^{\circ} \mathrm{C}$ until analysis. Approval of the Institutional Review Board of New York State Department of Health was obtained for the analysis of targeted biomarkers in urine.

\section{Results and discussion}

Methods to analyze effect biomarkers in human specimens have thus far been focused on assessing a single class of chemicals, with similar physicochemical properties, at a time. Recently, however, we reported the simultaneous analysis of seven urinary biomarkers of the oxidation of lipids, proteins, DNA, and uric acid and highlighted the feasibility and utility of monitoring multiple biomarkers of health effects so as to elucidate adverse outcome pathways[25]. In the current study, we augmented that method to include biomarkers of nitrative stress, eosinophilia, neutrophilia, and metabolic disorders to help describe interactions between these effect biomarkers in disease pathogenesis.

From analytical point of view, and in regard to structural similarities of the target compounds, the 19 biomarkers can be grouped as (i) modified tyrosines: diY, CY, BY, and NY; (ii) DNA/RNA lesion products: $8-\mathrm{OHdG}, 8-\mathrm{HG}, 8-\mathrm{HdG}$, 8-NG, and 8-NdG; (iii) aldehyde derivatives: MDA, HNEGHS, and HNE-MA; (iv) prostaglandin isomers: 8-PGF $2 \alpha$, 11-PGF ${ }_{2 \alpha}, 15-\mathrm{PGF}_{2 \alpha}$, and 8,15-PGF $2 \alpha$; and (v) highly polar AGE biomarkers: CML, CEL, and Alla.

\section{Method performance}

The sensitivity, accuracy, and precision of the method were determined through the analysis of synthetic and pooled urine samples fortified with target chemicals at three different concentrations (see the "Materials and methods" section for details). An optimal precision and accuracy were demonstrated for all biomarkers (Table 3). The intra-day RSD of the method was $<13 \%$ and the inter-day RSD was $<15 \%$ for all of the target analytes. Recoveries of target analytes spiked into urine matrices ranged from $91 \%$ for $8,15-\mathrm{PGF}_{2 \alpha}, \mathrm{NY}$, and CEL to $116 \%$ for $11-\mathrm{PGF}_{2 \alpha}$. The sensitivity of the method, expressed as mLOD and mLOQ, is acceptable based on the expected concentrations of the target analytes in urine. The mLODs ranged

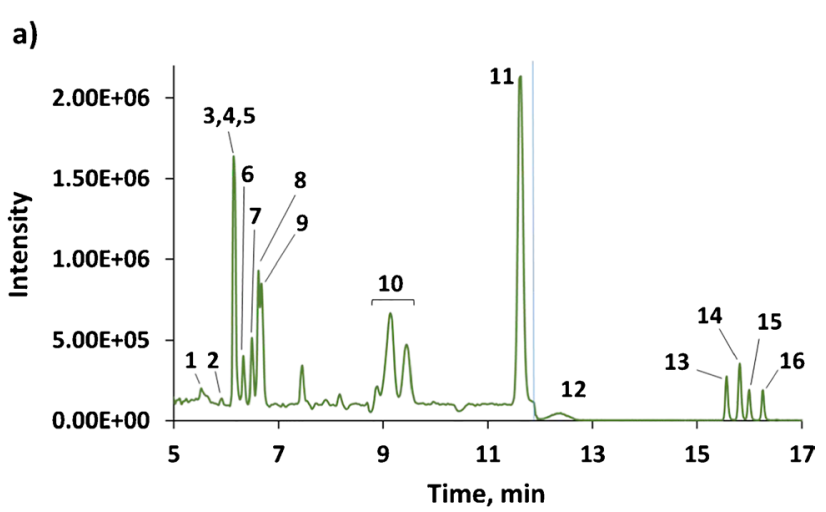

Fig. 2 HPLC-MS/MS chromatograms of biomarkers of health effects analyzed in the study (analytical standards injected at $10 \mathrm{ng} \mathrm{mL}^{-1}$; injection volume $20 \mu \mathrm{L}$ ). Shown are TIC (a) and XIC (b) values of 16 urinary biomarkers of health effects: (1) diY and ${ }^{13} \mathrm{C}_{12}$ diY, (2) 8-HdG, (3) 8-OHdG and ${ }^{15} \mathrm{~N}_{5}-8-\mathrm{OHdG}$, (4) 8-HG, (5) CY, (6) 8-NG, (7) BY and ${ }^{13} \mathrm{C}_{9^{-}}{ }^{15} \mathrm{~N}-\mathrm{BY}$, (8) 8-NdG, (9) $\mathrm{NY}$ and ${ }^{13} \mathrm{C}_{6^{-}}$ NY, (10) HNE-GHS, (11) MDA and D2-MDA, (12) HNE-MA and $\mathrm{D}_{3}$-HNE-MA, (13) 8,15-PGF $2 \alpha$, (14) 8-PGF $2 \alpha$ and $\mathrm{D}_{4}-8-\mathrm{PGF}_{2 \alpha}$, (15) $11-\mathrm{PGF}_{2 \alpha}$, and (16) $15-\mathrm{PGF}_{2 \alpha}$. XIC for AGEs (17) CML and $\mathrm{D}_{4}$-CML, (18) CEL (c) and (19) Alla and ${ }^{13} \mathrm{C}_{2}{ }^{15} \mathrm{~N}_{4}$-Alla (d) 
b)
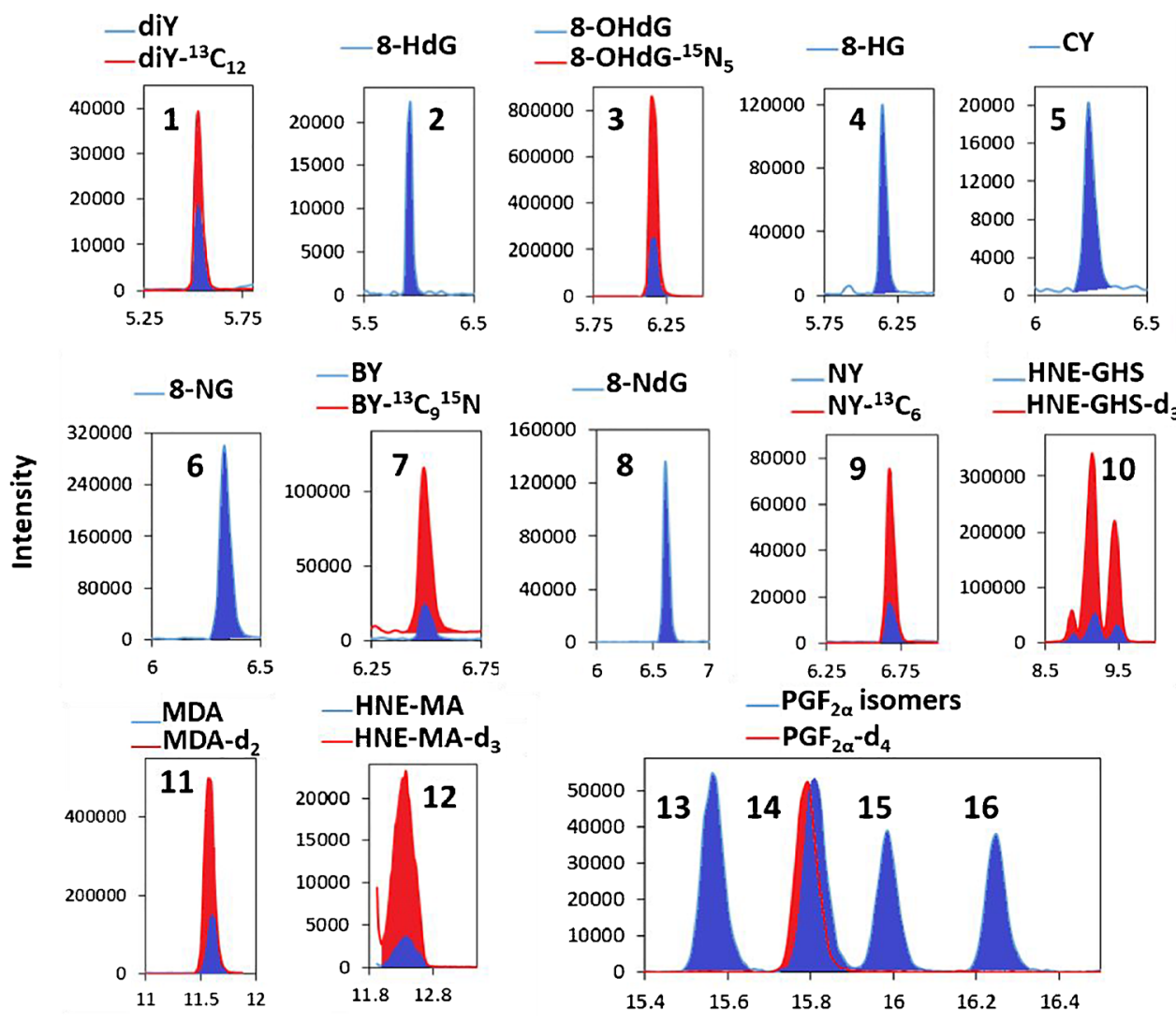

$-\mathrm{BY}$
$-\mathrm{BY}-{ }^{13} \mathrm{C}_{9}{ }^{15} \mathrm{~N}$
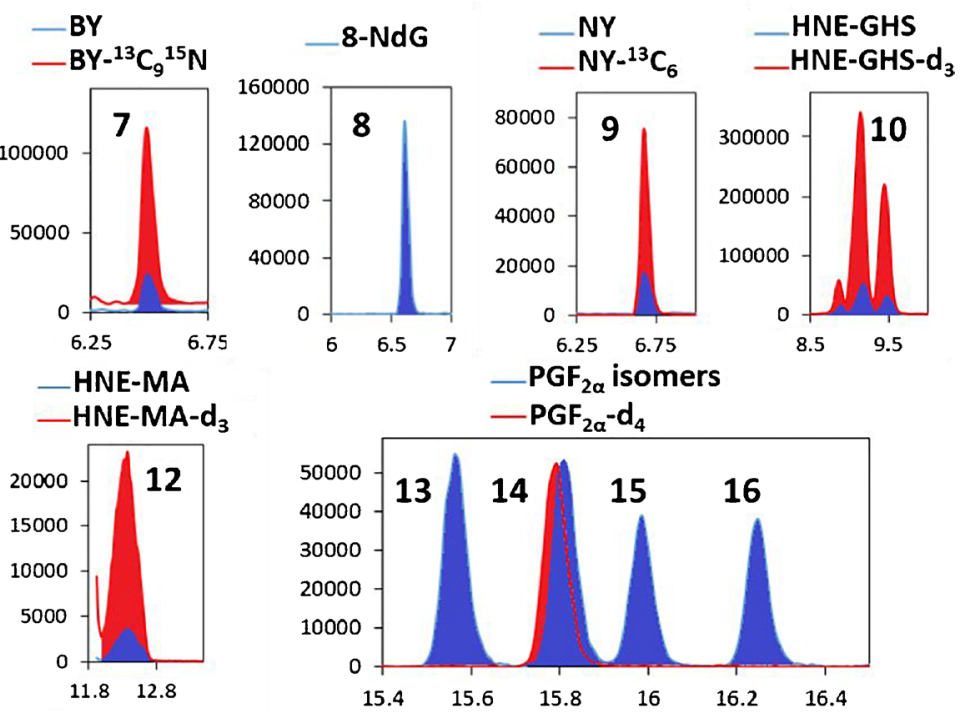

Time, $\min$

c)

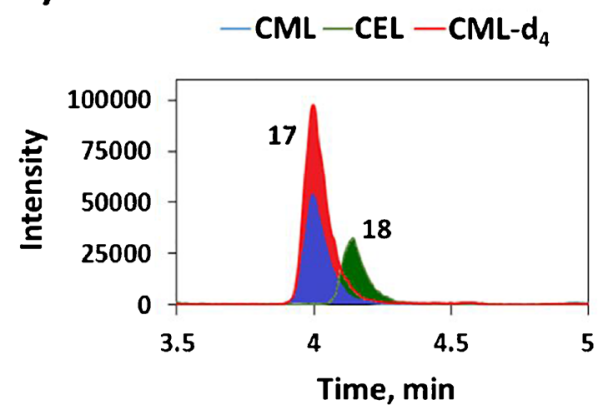

d)

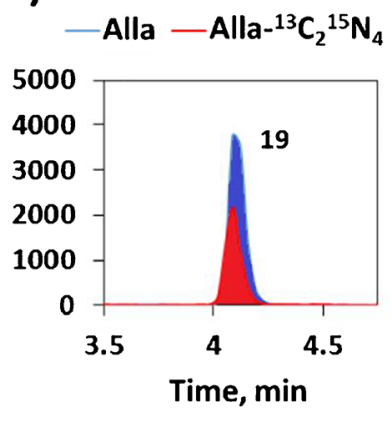

Fig. 2 (continued)

from $0.013 \mathrm{ng} \mathrm{mL}^{-1}$ for $\mathrm{PGF}_{2 \alpha}$ isomers to $0.36 \mathrm{ng} \mathrm{mL}^{-1}$ for HNE-MA (Table 3).

No significant matrix effects were observed when slopes of calibration graphs were constructed using synthetic urine and real urine samples $(\alpha=0.05)$ matched against the standards prepared in solvent.

\section{Application of the method}

We applied the method to analyze urine samples collected from 20 healthy volunteers (10 male, 10 female) from the Albany area of New York State. Of the 19 biomarkers assayed, we detected 8 in $100 \%$ of the samples: MDA, HNE-MA, 8-OHdG, 8-HdG, Alla, diY, CML, and CEL. 8-HG (95\%), 8-PGF ${ }_{2 \alpha}(90 \%)$, and $11-\mathrm{PGF}_{2 \alpha}$ and 
$8,15-\mathrm{PGF}_{2 \alpha}(80 \%)$ were frequently detected. Other OSB biomarkers were found in $<75 \%$ of samples. The modified tyrosine NY was found in $90 \%$ of samples, whereas $8-\mathrm{NG}$ and $8-\mathrm{NdG}$ were found in $55 \%$ and $45 \%$ of samples, respectively. Inflammation biomarkers (CY and BY) were found in $90-95 \%$ of samples. The metabolic disorder biomarkers CML and CEL were found in all urine samples (Fig. 3).

The concentrations of Alla were significantly higher [22] $\left(6300 \mu \mathrm{mol} \mathrm{mol} \mathrm{Cr}{ }^{-1}\right)$ than those of other OSBs. MDA and HNE-MA showed median concentrations of 11.9

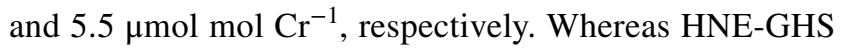
was found only at trace levels (median below LOQ), its metabolite HNE-MA occurred at concentrations of up to $128 \mathrm{ng} \mathrm{mL}^{-1}$. The two biomarkers of nucleic acid oxidation, 8-NG and 8-NdG, were found at similar median concentrations $\left(0.35 \mu \mathrm{mol} \mathrm{mol} \mathrm{Cr}^{-1}\right)$, while $\mathrm{NY}$ was found at a median concentration of $0.14 \mu \mathrm{mol} \mathrm{mol} \mathrm{Cr}{ }^{-1}$. BY and CY levels were similar $\left(0.27\right.$ and $\left.0.20 \mu \mathrm{mol} \mathrm{mol} \mathrm{Cr}{ }^{-1}\right)$, whereas the concentrations of AGEs ranged from $2.33 \mu \mathrm{mol} \mathrm{mol} \mathrm{Cr}^{-1}$ for CEL to $4.35 \mu \mathrm{mol} \mathrm{mol} \mathrm{Cr}{ }^{-1}$ for CML (Table 4).

The concentrations and profiles of individual health-effect biomarkers may be used to elucidate the health status of individuals (Fig. 3). Notably, the distribution pattern of the 19 biomarkers we tested was quite varied among 20 healthy individuals. Further studies should focus on establishing baseline levels and profiles for these biomarkers in a healthy population and assessing what factors affect their concentrations in urine.

\section{Significance of effect biomarkers in disease conditions}

\section{Biomarkers of protein damage: diY, NY, CY, and BY}

Oxidative stress, nitrative stress, neutrophilia, and eosinophilia can all damage proteins and generate modified tyrosines, namely diY, NY, CY, and BY, respectively. These four compounds have been measured individually using immunoassays and gas chromatography (GC)/LC-MS methods [17, $28,32]$. For example, all four have been previously assessed in diabetic patients [17] and asthmatic individuals [28], and $\mathrm{NY}, \mathrm{CY}$, and BY have been measured in urine from pregnant woman to elucidate their association with exposure to estrogenic chemicals [13]. Urinary NY concentrations are associated with BPA exposure [16] (Table 5).

\section{DNA and RNA lesion products}

Oxidized species of the nucleoside guanosine include 8-OHdG, 8-HG, and 8-NG, which are biomarkers of DNA damage, as well as $8-\mathrm{HdG}$ and $8-\mathrm{NdG}$, biomarkers of RNA damage. $8-\mathrm{OHdG}$ is the OSB commonly measured
A. OSBs profile

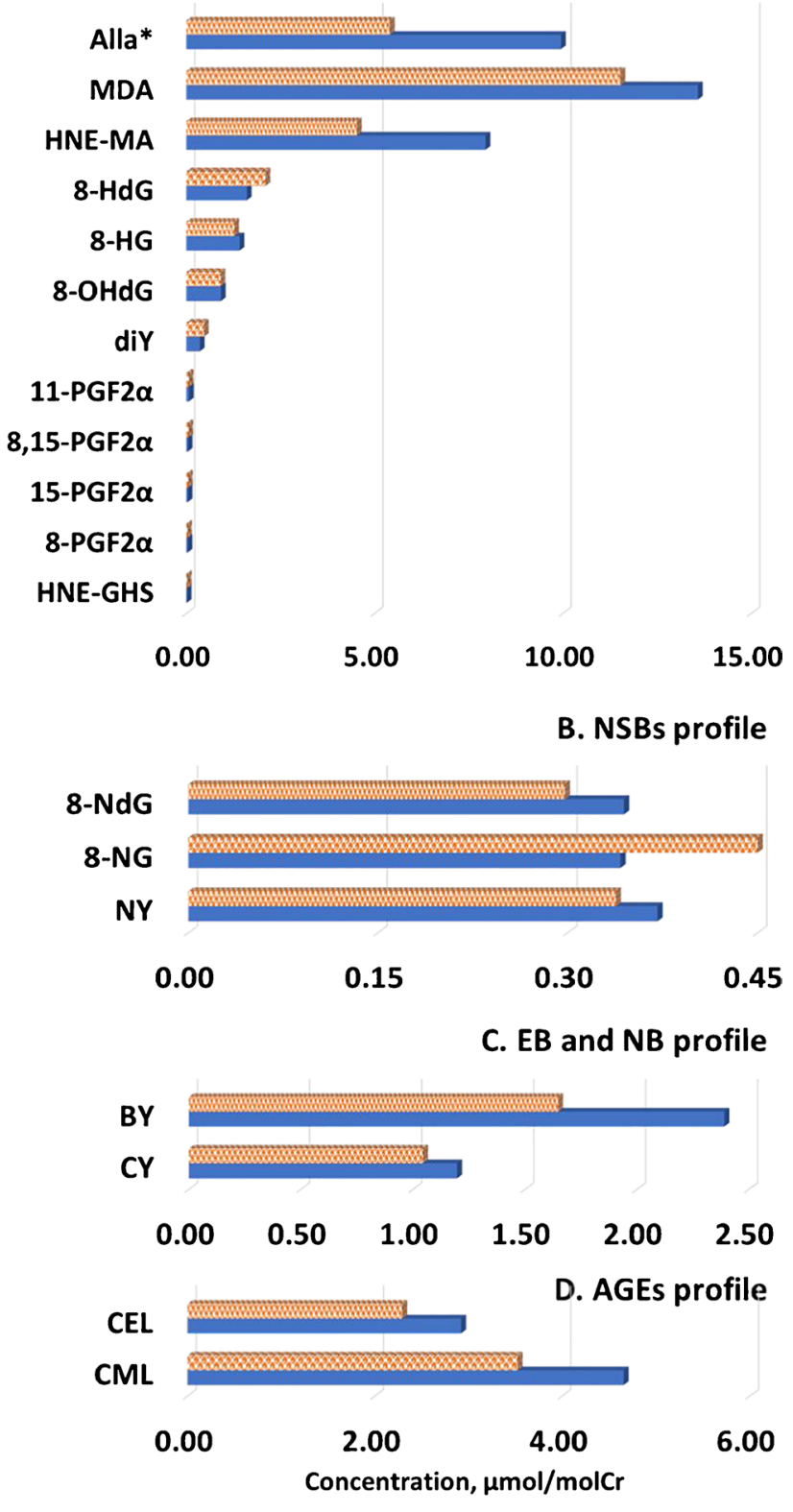

Fig. 3 Abundance of OSBs, NSBs, IBs, and AGEs measured in male (solid blue, $n=10$ ) and female (orange pattern, $n=10$ ) urine samples analyzed using the method developed in this study. (A) Oxidative stress biomarkers; (B) nitrative stress biomarkers; (C) inflammation biomarkers; and (D) metabolic disorder biomarkers (AGEs). Levels are expressed in $\mu \mathrm{mol} \mathrm{mol} \mathrm{Cr}^{-1}$ except those for Alla (denoted *), which are expressed in $\mathrm{mmol} \mathrm{mol} \mathrm{Cr}^{-1}$

in environmental health investigations. Studies have linked exposure to phthalates [14, 33-35], BPA [15, 16], organophosphate esters (OPEs) [36], or pesticides [37, 38] with elevated urinary 8 -OHdG. Simultaneous determination of 8-OHdG and 8-NG has been used to assess link between oxidative and/or nitrative damage and exposures to per- and polyfluoroalkyl substances [12], phthalates [14], or BPA 
Table 4 Urinary concentrations of 19 biomarkers of oxidative stress, nitrative stress, eosinophilia, neutrophilia, and metabolic disorders in healthy individuals $(N=20,10$ males, 10 females $)$

\begin{tabular}{|c|c|c|c|c|c|c|c|}
\hline \multirow[t]{2}{*}{ 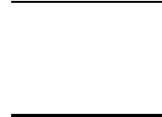 } & \multirow[t]{2}{*}{$\mathrm{DF}, \%$} & \multicolumn{3}{|c|}{ Volumetric concentrations, $\mathrm{ng} \mathrm{mL}^{-1}$} & \multicolumn{3}{|c|}{ Adjusted concentrations, $\mu \mathrm{mol} \mathrm{mol} \mathrm{Cr}^{-1}$} \\
\hline & & Maximum & Median & Minimum & Maximum & Median & Minimum \\
\hline MDA & 100 & 84.3 & 11.9 & 1.46 & 31.6 & 11.9 & 3.27 \\
\hline HNE-GHS & 75 & 0.30 & $<\operatorname{LOQ}(0.08)$ & $<\mathrm{LOD}$ & 0.053 & 0.013 & $<\mathrm{LOD}$ \\
\hline HNE-MA & 100 & 128 & 21.8 & 2.85 & 38.6 & 5.50 & 0.48 \\
\hline $8-\mathrm{PGF}_{2 \alpha}$ & 90 & 1.95 & 0.12 & $<$ LOD & 0.11 & 0.028 & $<$ LOD \\
\hline $11-\mathrm{PGF}_{2 \alpha}$ & 80 & 1.75 & 0.31 & $<$ LOD & 0.33 & 0.064 & $<$ LOD \\
\hline $15-\mathrm{PGF}_{2 \alpha}$ & 55 & 2.56 & 0.17 & $<\mathrm{LOD}$ & 0.18 & 0.042 & $<\mathrm{LOD}$ \\
\hline $8,15-\mathrm{PGF}_{2 \alpha}$ & 80 & 2.75 & 0.14 & $<\mathrm{LOD}$ & $0.78 \alpha$ & 0.040 & $<\mathrm{LOD}$ \\
\hline 8-OHdG & 100 & 14.2 & 3.44 & 0.95 & 1.70 & 0.90 & 0.27 \\
\hline 8-HG & 95 & 24.7 & 2.63 & $<$ LOD & 3.80 & 1.39 & $<$ LOD \\
\hline 8-HdG & 100 & 48.9 & 6.35 & 1.29 & 3.39 & 1.87 & 0.49 \\
\hline Alla & 100 & 86200 & 14100 & 2030 & 20200 & 6300 & 940 \\
\hline $\operatorname{diY}$ & 100 & 8.55 & 2.44 & 0.40 & 1.20 & 0.38 & 0.13 \\
\hline 8-NG & 55 & 5.86 & 0.80 & $<\mathrm{LOD}$ & 1.32 & 0.35 & $<$ LOD \\
\hline 8-NdG & 45 & 12.1 & 1.46 & $<\mathrm{LOD}$ & 1.26 & 0.34 & $<$ LOD \\
\hline NY & 90 & 28.1 & 0.36 & $<$ LOD & 0.89 & 0.14 & $<$ LOD \\
\hline BY & 90 & 23.0 & 0.51 & $<\mathrm{LOD}$ & 2.32 & 0.27 & $<$ LOD \\
\hline $\mathrm{CY}$ & 95 & 22.3 & 0.50 & $<\mathrm{LOD}$ & 1.50 & 0.20 & $<$ LOD \\
\hline CML & 100 & 41.3 & 12.9 & 1.40 & 10.4 & 4.35 & 1.44 \\
\hline CEL & 100 & 19.9 & 8.9 & 1.48 & 6.05 & 2.33 & 0.85 \\
\hline
\end{tabular}

Table 5 Published studies reporting a link between environmental chemical exposures, oxidative/nitrative stress, inflammation, and adverse health outcomes

\begin{tabular}{|c|c|c|c|}
\hline Exposure & Biomarkers & Health outcome & Ref \\
\hline Endocrine-disrupting chemicals & ONS + IB: NY, diY, CY & Birth outcomes & {$[13]$} \\
\hline Phthalates & OS: 8 -OHdG, HNE-MA and 8-PGF $2 \alpha$ & Thyroid function & [33] \\
\hline Phthalates & ONS: 8-OHdG, 8-NG and MDA & Thyroid function & {$[14]$} \\
\hline Phthalates & OS: diY, MDA, 8-OHdG, $4 \mathrm{PGF}_{2 \alpha}$ isomers & Diabetes & [40] \\
\hline Phthalates & OS: $8-\mathrm{OHdG}$ and $8-\mathrm{PGF}_{2 \alpha}$ & Birth outcomes & [44] \\
\hline Phthalates and alternatives & OS: 8-PGF $2 \alpha$ /prostaglandin $\mathrm{F}_{2 \alpha}$ & Inflammation & [35] \\
\hline BDE-153 & ONS: MDA, and NO & Neurotoxicity & [41] \\
\hline Perfluoroalkyl substances & ONS: $8-\mathrm{OHdG}$ and 8-NG & Lipid profiles & {$[12]$} \\
\hline OPFRs & OS: 8-OHdG, 4-HNE, HEL & & [48] \\
\hline Pesticides & OS: diY, MDA, 8-OHdG, $4 \mathrm{PGF}_{2 \alpha}$ isomers & & [37] \\
\hline Neonicotinoids & OS: diY, MDA, 8-OHdG, $4 \mathrm{PGF}_{2 \alpha}$ isomers & & [38] \\
\hline Nonylphenol and BPA & ONS: 8 -OHdG, HNE-MA, $8-\mathrm{PGF}_{2 \alpha}, 8-\mathrm{NG}$ & Fetal reproductive indices & {$[15]$} \\
\hline BPA & ONS + IB: NY, diY, CY & Developmental exposure effects & [16] \\
\hline BPA, BPS, BPF & OS: 8-OHdG, HNE-MA, 8-PGF ${ }_{2 \alpha}$, & & {$[43]$} \\
\hline
\end{tabular}

$H E L$, hexanoyllysine; $N O$, nitric oxide; $O S$, oxidative stress; $O N S$, oxidative and nitrative stress

[15]. Oxidized serum guanine (e.g., 8-OHdG, 8-HG, 8-HdG) has been associated with COVID-19 mortality [39], and elevated serum levels of $8-\mathrm{HG}, 8-\mathrm{HdG}$, or $8-\mathrm{NdG}$ have been linked to mortality associated with traumatic brain injury [18].

\section{Aldehyde derivatives: MDA, HNE-GHS, and HNE-MA}

The oxidation of lipids results in the formation of an array of biomolecules that are excreted in urine. Oxidation of polyunsaturated acids (PUFA) generates aldehydes, such as MDA and 4-hydroxynonenal (4-HNE). Because aldehydes are 
highly reactive, their direct determination in urine is challenging. The most commonly used method to detect MDA is the thiobarbituric acid (TBA) assay, but this is known to lack selectivity. Accurate and selective determination of urinary MDA has been successfully accomplished through its derivatization with DNPH followed by HPLC-MS/MS analysis of the stable product, MDA-DNPH. Urinary MDA concentrations have been associated with phthalate exposures and with thyroid dysfunction [14] and diabetes [40]. Similarly, MDA levels have been positively correlated with exposure to brominated diphenyl ethers [41] or organophosphate pesticides and neonicotinoid insecticides [37, 38].

4-HNE forms an adduct with the antioxidant glutathione, producing 4-HNE-GHS [19, 42], which in turn is metabolized and excreted as 4-HNE-MA conjugate in urine. Studies have associated 4-HNE-MA with thyroid dysfunction and phthalate exposure [33] and with adverse fetal outcomes and bisphenol exposure [15, 43]. No studies have reported the simultaneous analysis of both HNE derivatives, along with MDA, and this study is the first to report the concurrent measurement of these biomarkers.

\section{Prostaglandin isomers: 8-PGF $2 a^{\prime} 11-\mathrm{PGF}_{2 a^{\prime}} 15-\mathrm{PGF}_{2 a^{\prime}}$ and $8,15-$ PGF $_{2 a}$}

The oxidation of arachidonic acid by ROS yields $\mathrm{F}_{2}$-isoprostanes, which comprise 64 different isomers. The reported method focused on the determination of four bioactive forms of $\mathrm{F}_{2}$-isoprostanes: 8- $\mathrm{PGF}_{2 \alpha}, 11-\mathrm{PGF}_{2 \alpha}$, $15-\mathrm{PGF}_{2 \alpha}$, and $8,15-\mathrm{PGF}_{2 \alpha} \cdot 8-\mathrm{PGF}_{2 \alpha}$ is the prostaglandin most frequently analyzed in studies relating thyroid dysfunction [33], birth outcomes [44], and inflammation [35]. The four isomers were simultaneously determined in a case-control study linking diabetes and phthalate exposure, showing that $8-\mathrm{PGF}_{2 \alpha}$ was positively correlated with urinary phthalate metabolites and high odd ratios for diabetes and two prostaglandin isomers, 8- $\mathrm{PGF}_{2 \alpha}$ and $15-\mathrm{PGF}_{2 \alpha}$ [34].

\section{Highly polar AGE biomarkers: CML, CEL, and Alla}

AGEs such as CML, CEL, and Alla are highly polar molecules (with $\mathrm{X} \log \mathrm{P} 3$ values $-2.2,-5.2$, and -5.3 , respectively) and are typically present at measurable concentrations in urine. Therefore, the identification and quantification of AGEs and Alla could be accomplished by a simple D\&S method with optimized LC-MS/MS parameters. Notably, Alla is produced by the reaction of uric acid, an important antioxidant, with ROS. It has been reported that Alla concentrations do not correlate with those of uric acid, but are positively correlated with the concentrations of other OSBs [22]. Nevertheless, very few studies have reported urinary concentrations of Alla in relation to adverse health effects.
AGEs are linked to metabolic disorders and oxidative stress $[20,45,46]$ and are generated under high glucose concentrations (hyperglycemia) via a nonenzymatic glycation pathway (Maillard reaction). During glycation, glucose binds with proteins, making cells stiffer, less pliable, and subject to premature aging. Glycation can be accelerated by heat or oxidative stress. AGEs such as CML have been used as biomarkers of chronic diseases, such as diabetes, atherosclerosis, and renal failure. Although CML can be present in diet, those levels are negligible compared with the magnitude of endogenous formation [47]. CML is formed when glyoxal (formed from oxidation of lipids and sugars) reacts with lysine. Similarly, methylglyoxal produces CEL, which can interact with AGE receptors (RAGEs) and disrupt cellular signaling [46]. Significant relationships between AGEs and diabetes, aging, cardiovascular and neurological diseases, and cancer have been documented in the literature $[45,47]$. To the best of our knowledge, however, little is known about any association between exposure to organic contaminants and AGE formation.

\section{Conclusions}

Here, we describe a method for the simultaneous analysis of 16 biomarkers of oxidative stress, nitrative stress, and inflammation; in addition, two metabolic disorder biomarkers and alla were measured in urine for a total of 19 effect biomarkers analyzed. The capability to analyze multiple biomarkers of health effects simultaneously that we demonstrated here could help elucidate the biological pathways underlying various types of pathogenesis. Also noteworthy is that when we used this method to analyze urine from 20 healthy individuals, we detected all 19 of these biomarkers of concern in some or all of those individuals.

Funding Research reported here was supported by the US National Institute of Environmental Health Sciences (NIEHS) under the award number U2CES026542. The content is solely the responsibility of the authors and does not necessarily represent the official views of the NIEHS.

\section{Declarations}

Conflict of interest The authors declare no competing interests.

\section{References}

1. Zeliger HI (2016) Causes, mechanisms and prevention of environmental diseases. Dual Diagnosis Open Access 01:1-18. https:// doi.org/10.21767/2472-5048.100001

2. Flies EJ, Mavoa S, Zosky GR, Mantzioris E, Williams C, Eri R, Brook BW, Buettel JC. Urban-associated diseases: candidate 
diseases, environmental risk factors, and a path forward. Environ Int. 2019;133: 105187. https://doi.org/10.1016/j.envint.2019. 105187.

3. Vrijheid M, Casas M, Gascon M, Valvi D, Nieuwenhuijsen M. Environmental pollutants and child health-a review of recent concerns. Int J Hyg Environ Health. 2016;219:331-42. https://doi.org/ 10.1016/j.ijheh.2016.05.001.

4. Liu Y, Wang J, Huang Z, Liang J, Xia Q, Xia Q, Liu X. Environmental pollutants exposure: a potential contributor for aging and age-related diseases. Environ Toxicol Pharmacol. 2021;83:103575. https://doi.org/10.1016/j.etap.2020.103575.

5. Kelly FJ, Fussell JC (2019) Metabolomics as a tool to unravel the oxidative stress-induced toxicity of ambient air pollutants. In: Oxidative Stress: Eustress and Distress. Elsevier, pp 463-488. https://doi.org/10.1016/B978-0-12-818606-0.00024-9.

6. Hu X, He L, Zhang J, Qiu X, Zhang Y, Mo J, Day DB, Xiang J, Gong J. Inflammatory and oxidative stress responses of healthy adults to changes in personal air pollutant exposure. Environ Pollut. 2020;263:114503. https://doi.org/10.1016/j.envpol.2020. 114503.

7. Jana K, C. P,. Environmental toxicants induced male reproductive disorders: identification and mechanism of action. Toxic Drug Test. 2012. https://doi.org/10.5772/29649.

8. Roberts RA, Laskin DL, Smith CV, Robertson FM, Allen EMG, Doorn JA, Slikker W. Nitrative and oxidative stress in toxicology and disease. Toxicol Sci. 2009;112:4-16. https://doi.org/10.1093/ toxsci/kfp179.

9. Gasparovic AC, Zarkovic N, Bottari SP. Biomarkers of nitro-oxidation and oxidative stress. Curr Opin Toxicol. 2018;7:73-80. https://doi.org/10.1016/j.cotox.2017.10.002.

10. Frijhoff J, Winyard PG, Zarkovic N, Davies SS, Stocker R, Cheng D, Knight AR, Taylor EL, Oettrich J, Ruskovska T, Gasparovic AC, Cuadrado A, Weber D, Poulsen HE, Grune T, Schmidt HHHW, Ghezzi P. Clinical relevance of biomarkers of oxidative stress. Antioxidants Redox Signal. 2015;23:1144-70. https://doi. org/10.1089/ars.2015.6317.

11. Aggarwal V, Tuli HS, Varol A, Thakral F, Yerer MB, Sak K, Varol M, Jain A, Khan MA, Sethi G (2019) Role of reactive oxygen species in cancer progression: molecular mechanisms and recent advancements. Biomolecules 9: https://doi.org/10.3390/biom9 110735

12. Lin CY, Lee HL, Hwang YT, Su TC. The association between total serum isomers of per- and polyfluoroalkyl substances, lipid profiles, and the DNA oxidative/nitrative stress biomarkers in middle-aged Taiwanese adults. Environ Res. 2020;182: 109064. https://doi.org/10.1016/j.envres.2019.109064.

13. Puttabyatappa M, Banker M, Zeng L, Goodrich JM, Domino SE, Dolinoy DC, Meeker JD, Pennathur S, Song PXK, Padmanabhan V. Maternal exposure to environmental disruptors and sexually dimorphic changes in maternal and neonatal oxidative stress. J Clin Endocrin Met. 2020;105:492-505. https://doi.org/10.1210/ clinem/dgz063

14. Huang PC, Waits A, Chen HC, Chang WT, Jaakkola JJK, Bin $\mathrm{HH}$. Mediating role of oxidative/nitrosative stress biomarkers in the associations between phthalate exposure and thyroid function in Taiwanese adults. Environ Int. 2020;140: 105751. https://doi. org/10.1016/j.envint.2020.105751.

15. Huang YF, Wang PW, Huang LW, Lin MH, Yang W, Chen HC, Yu KP, Chen ML. Interactive effects of nonylphenol and bisphenol A exposure with oxidative stress on fetal reproductive indices. Environ Res. 2018;167:567-74. https://doi.org/10.1016/j.envres. 2018.08.007.

16. Veiga-Lopez A, Pennathur S, Kannan K, Patisaul HB, Dolinoy DC, Zeng L, Padmanabhan V. Impact of gestational bisphenol A on oxidative stress and free fatty acids: human association and interspecies animal testing studies. Endocrinology. 2015;156:91122. https://doi.org/10.1210/en.2014-1863.

17. Kato Y, Dozaki N, Nakamura T, Kitamoto N, Yoshida A, Naito M, Kitamura M, Osawa T. Quantification of modified tyrosines in healthy and diabetic human urine using liquid chromatography/ tandem mass spectrometry. J Clin Biochem Nutr. 2009;44:67-78. https://doi.org/10.3164/jcbn.08-185.

18. Lorente L, Martín MM, González-Rivero AF, Pérez-Cejas A, Abreu-González P, Ramos L, Argueso M, Cáceres JJ, Solé-Violán J, Alvarez-Castillo A, Jiménez A, García-Marín V. Association between DNA and RNA oxidative damage and mortality of patients with traumatic brain injury. Neurocrit Care. 2020;32:7905. https://doi.org/10.1007/s12028-019-00800-w.

19. Alary J, Guéraud F, Cravedi JP. Fate of 4-hydroxynonenal in vivo: disposition and metabolic pathways. Mol Aspects Med. 2003;24:177-87. https://doi.org/10.1016/S0098-2997(03) 00012-8.

20. Il D, Scarbrough P, Spasojevic I. Urinary biomarkers of oxidative status. Clin Chim Acta. 2012;413:1446-53. https://doi.org/ 10.1016/j.cca.2012.06.012.

21. Aszyk J, Kot J, Tkachenko Y, Woźniak M, Bogucka-Kocka A, Kot-Wasik A. Novel liquid chromatography method based on linear weighted regression for the fast determination of isoprostane isomers in plasma samples using sensitive tandem mass spectrometry detection. J Chromatogr B Anal Technol Biomed Life Sci. 2017;1051:17-23. https://doi.org/10.1016/j.jchromb.2017.02.021.

22. Martinez-Moral M-P, Kannan K (2019) Allantoin as a marker of oxidative stress: inter- and intraindividual variability in urinary concentrations in healthy individuals. Environ Sci Technol Lett 6: https://doi.org/10.1021/acs.estlett.9b00142

23. Isa KNM, Hashim Z, Jalaludin J, Than LTL, Hashim JH. The effects of indoor pollutants exposure on allergy and lung inflammation: an activation state of neutrophils and eosinophils in sputum. Int J Environ Res Public Health. 2020;17:1-18. https://doi. org/10.3390/ijerph17155413.

24. Vetrano AM, Laskin DL, Archer F, Syed K, Gray JP, Laskin JD, Nwebube N, Weinberger B. Inflammatory effects of phthalates in neonatal neutrophils. Pediatr Res. 2010;68:134-9. https://doi.org/ 10.1203/PDR.0b013e3181e5c1f7.

25. Loffredo LF, Berdnikovs MECS (2020) Endocrine disruptor bisphenol a (BPA) triggers systemic para-inflammation and is sufficient to induce airway allergic sensitization in mice. Nutrients 12: https://doi.org/10.3390/nu12020343

26. Kovalszki A, Weller PF, Israel B. Eosiniophilia. Prim Care. 2016;43:607-17. https://doi.org/10.1016/j.pop.2016.07.010.Eosin ophilia.

27. Buss IH, Senthilmohan R, Darlow BA, Mogridge N, Kettle AJ, Winterbourn CC. 3-Chlorotyrosine as a marker of protein damage by myeloperoxidase in tracheal aspirates from preterm infants : association with adverse respiratory outcome. Pediatric Res. 2003;53:455-62. https://doi.org/10.1203/01.PDR.0000050655. 25689.CE

28. Mita H, Higashi N, Taniguchi M, Higashi A, Kawagishi Y, Akiyama K. Urinary 3-bromotyrosine and 3-chlorotyrosine concentrations in asthmatic patients : lack of increase in 3-bromotyrosine concentration in urine and plasma proteins in aspirin-induced asthma after intravenous aspirin challenge. Clin Exp Allergy. 2004;34:931-8. https://doi.org/10.1111/j.1365-2222.2004. 01968.x

29. Diamanti-Kandarakis E, Bourguignon J-P, Giudice LC, Hauser R, Prins GS, Soto AM, Zoeller RT, Gore AC. Endocrine-disrupting chemicals: an Endocrine Society scientific statement. Endocr Rev. 2009;30:293-342. https://doi.org/10.1210/er.2009-0002. 
30. Schleicher E, Friess U. Oxidative stress, AGE, and atherosclerosis. Kidney Int. 2007;72:S17-26. https://doi.org/10.1038/sj.ki.50023 82.

31. Martinez MP, Kannan K. Simultaneous analysis of seven biomarkers of oxidative damage to lipids, proteins, and DNA in urine. Environ Sci Technol 2018;52:6647-55. https://doi.org/10.1021/ acs.est. 8 b00883

32. Gaut JP, Byun J, Tran HD, Heinecke JW. Artifact-free quantification of free 3-chlorotyrosine , 3-bromotyrosine , and 3-nitrotyrosine in human plasma by electron capture - negative chemical ionization gas chromatography mass spectrometry and liquid chromatography - electrospray ionization tandem mass spectrometry. Anal Biochem. 2002;259:252-9. https://doi.org/10. 1006/abio.2001.5469

33. Zhang M, Deng YL, Liu C, Chen PP, Luo Q, Miao Y, Cui FP, Wang LQ, Jiang M, Zeng Q. Urinary phthalate metabolite concentrations, oxidative stress and thyroid function biomarkers among patients with thyroid nodules. Environ Pollut. 2021;272: 116416. https://doi.org/10.1016/j.envpol.2020.116416.

34. Li AJ, Martinez-Moral M-P, Al-Malki AL, Al-Ghamdi MA, AlBazi MM, Kumosani TA, Kannan K (2019) Mediation analysis for the relationship between urinary phthalate metabolites and type 2 diabetes via oxidative stress in a population in Jeddah, Saudi Arabia. Environ Int 126: https://doi.org/10.1016/j.envint.2019.01. 082

35. Van'TErve TJ, Rosen EM, Barrett ES, Nguyen RHN, Sathyanarayana S, Milne GL, Calafat AM, Swan SH, Ferguson KK. Phthalates and phthalate alternatives have diverse associations with oxidative stress and inflammation in pregnant women. Environ Sci Technol. 2019. https://doi.org/10.1021/acs.est.8b05729.

36. Wang Y, Li W, Martínez-Moral MP, Sun H, Kannan K (2019) Metabolites of organophosphate esters in urine from the United States: concentrations, temporal variability, and exposure assessment. Environ Int 122: https://doi.org/10.1016/j.envint.2018.11. 007

37. Li AJ, Martinez-Moral MP, Kannan K. Temporal variability in urinary pesticide concentrations in repeated-spot and firstmorning-void samples and its association with oxidative stress in healthy individuals. Environ Int. 2019;130: 104904. https://doi. org/10.1016/j.envint.2019.104904.

38. Li AJ, Martinez-Moral MP, Kannan K. Variability in urinary neonicotinoid concentrations in single-spot and first-morning void and its association with oxidative stress markers. Environ Int. 2020;135: 105415. https://doi.org/10.1016/j.envint.2019.105415.

39. Lorente L, Martín MM, González-Rivero AF, Pérez-Cejas A, Cáceres JJ, Perez A, Ramos-Gómez L, Solé-Violán J, Marcos y Ramos JA, Ojeda N, Jiménez A (2021) DNA and RNA oxidative damage and mortality of patients with COVID-19. Am J Med Sci 1-6. https://doi.org/10.1016/j.amjms.2021.02.012

40. Li AJ, Martinez-Moral MP, Al-Malki AL, Al-Ghamdi MA, AlBazi MM, Kumosani TA, Kannan K. Mediation analysis for the relationship between urinary phthalate metabolites and type 2 diabetes via oxidative stress in a population in Jeddah, Saudi Arabia. Environ Int. 2019;126:153-61. https://doi.org/10.1016/j. envint.2019.01.082.

41. Zhang H, Yang X, Li X, Cheng Y, Zhang H, Chang L, Sun M, Zhang Z, Wang Z, Niu Q, Wang T. Oxidative and nitrosative stress in the neurotoxicity of polybrominated diphenyl ether-153: possible mechanism and potential targeted intervention. Chemosphere. 2020;238: 124602. https://doi.org/10.1016/j.chemosphere.2019. 124602.

42. Völkel W, Alvarez-Sánchez R, Weick I, Mally A, Dekant W, Pähler A. Glutathione conjugates of 4-hydroxy-2(E)-nonenal as biomarkers of hepatic oxidative stress-induced lipid peroxidation in rats. Free Radic Biol Med. 2005;38:1526-36. https://doi.org/ 10.1016/j.freeradbiomed.2005.02.015.

43. Wang YX, Liu C, Shen Y, Wang Q, Pan A, Yang P, Chen YJ, Deng YL, Lu Q, Cheng LM, Miao XP, Xu SQ, Lu WQ, Zeng Q. Urinary levels of bisphenol A, F and $\mathrm{S}$ and markers of oxidative stress among healthy adult men: variability and association analysis. Environ Int. 2019;123:301-9. https://doi.org/10.1016/j. envint.2018.11.071.

44. Ferguson KK, Cantonwine DE, Rivera-González LO, LochCaruso R, Mukherjee B, Anzalota Del Toro LV, Jiménez-Vélez B, Calafat AM, Ye X, Alshawabkeh AN, Cordero JF, Meeker JD. Urinary phthalate metabolite associations with biomarkers of inflammation and oxidative stress across pregnancy in Puerto Rico. Environ Sci Technol. 2014;48:7018-25. https://doi.org/10. 1021/es502076j.

45. Ighodaro OM. Biomedicine \& Pharmacotherapy Molecular pathways associated with oxidative stress in diabetes mellitus. Biomed Pharmacother. 2018;108:656-62. https://doi.org/10.1016/j.biopha. 2018.09.058.

46. Vistoli G, Maddis D De, Cipak A, Zarkovic N, Carini M, Aldini G, Maddis D De, Cipak A, Zarkovic N, Carini M, Aldini G. Advanced glycoxidation and lipoxidation end products (AGEs and ALEs): an overview of their mechanisms of formation. Free Rad Res. 2013;47:3-27. https://doi.org/10.3109/10715762.2013. 815348

47. End-products G, Zeng C, Li Y, Ma J, Niu L, Tay FR. Clinical / translational aspects of advanced. Trends Endocrinol Metab. 2019;30:959-73. https://doi.org/10.1016/j.tem.2019.08.005.

48. AitBamai Y, Bastiaensen M, Araki A, Goudarzi H, Konno S, Ito S, Miyashita C, Yao Y, Covaci A, Kishi R. Multiple exposures to organophosphate flame retardants alter urinary oxidative stress biomarkers among children: the Hokkaido Study. Environ Int. 2019;131: 105003. https://doi.org/10.1016/j.envint.2019.105003.

Publisher's note Springer Nature remains neutral with regard to jurisdictional claims in published maps and institutional affiliations. 